\title{
Cytological and Molecular Studies Based on Ovarian Nurse Cell's Polytene Chromosome and ITS-2 Sequence of Anopheles vagus in West Bengal
}

\author{
S. Paul and P.K.Banerjee \\ Vector Molecular Genetics Research Unit, Dept. of Zoology (UG and PG), Serampore College, \\ Serampore, Hooghly, West Bengal, India. \\ pkbjan1961@gmail.com
}

\begin{abstract}
An.vagus is medically important vector and is associated with the transmission of malaria in some places of north east India and Bangladesh. Studies on the cytogenetics of An.vagus mosquitoes have been extended through the observation of banding and puffing pattern of polytene chromosome. Cytological and Molecular variation of An. vagus is manifested through the polytene chromosome (inversion and translocation) and ITS2 sequence respectively. In West Bengal studies on cytogenetics and molecular genetics of An. vagus is very poor, therefore we have undertaken our research work on polytene chromosome and ITS 2 Sequence to know the cytological and molecular variation of An. vagus in natural population.
\end{abstract}

Keywords: An.vagus, polytene chromosome, ITS 2.

\section{INTRODUCTIONS}

Anopheles vagus is a medically important vector and associated with the transmission of malaria parasite in some places of north east India and Bangladesh ${ }^{(1)}$. The species An. vagus mostly prefer to reside in cattle shed and human dwelling ${ }^{(10)}$. Earlier a few scientists ${ }^{(3,6,8)}$ had done their pioneer investigation on the genetics and cytogenetics of mosquitoes. Studies on the cytogenetics of Anopheles mosquitoes have been extended not only through the preparation of polytene chromosome but also through the observation of banding and puffing pattern of the polytene chromosome. Preparation of polytene chromosome from salivary gland of An vagus has been initiated previously ${ }^{(6)}$. Several scientists $(5,12,15,16,17,18)$ extended their cytological work in ovarian nurse cell's polytene chromosome to know the taxonomoic status as well as cytological variation in Anopheles mosquitoes in natural and laboratory population. Cytological and molecular variation in Anopheles is manifested through variation (mainly in inversion and translocation) in polytene chromosome. The cytogenetic variation in malaria vectors provide some valuable information about the genetic basis of vectorial attribute and insecticide resistance.

For proper identification and construction of phylogenetic tree, internal transcribed region of rDNA is extensively used. As ITS2 is very faster evolving region it is also efficiently used for the characterization and discrimination of closely related species. Several scientist ${ }^{(9,11,19)}$ extended their studies on the molecular variation in Anopheles mosquitoes through PCR based assay for internal transcribed spacer 2 (noncoding region) of rDNA. It is very important to emphasize on details knowledge of studying morphological, cytological and the molecular status of An. vagus in order to establish a proper control measure.

But in West Bengal, studies on genetics and cytogenetics of Anopheles are very little. Earlier some cytogenetic research works have been done in Anopheles mosquitoes ${ }^{(4,5,14,15)}$. But their work is confined to An. subpictus. Therefore, we have undertaken the cytological and molecular studies on An. vagus to know its cytological and molecular variation in natural population.

\section{MATERIALS AND METHODS}

\subsection{Collection of Sample}

A wild strain of adult female Anopheles mosquitoes were collected between $8 \mathrm{am}$ to 10 am from cattle shed of different areas of West Bengal. They were collected by using manual aspirator. Without any 
injury, that specimen, were transferred to the air tight ependrof. After identifying the specimen (using Identification key ${ }^{(7,13)}$ they were visualized by using Dewinter Seteriomacroscope and the semi gravid female of An. vagus were used for cytological studies through the preparation of Polytene chromosome and some of them were preserved for molecular studies through genomic DNA isolation.

\subsection{Preparation of Polytene Chromosome}

Ovaries were pulled out from the semi gravid females and polytene chromosomes were prepared from the ovarian nurse cells of An vagus females followed by the standard methods ${ }^{(5,16)}$.

\subsection{DNA Isolation and PCR Amplification}

DNA was isolated from individual adult mosquitoes by phenol chloroform extraction by Standered protocol ${ }^{(2)}$. The ITS2 region of $\mathrm{r}$ DNA was amplified using the specific forward and reverse primer (FP, RP) consisting of 20-21 base oligomers having the sequence 5'TGTGAACTGCAGGACA CACAT-3' (CODE 46JB) and 5'- TGTGCTTAAATTCAGGGGGT-3' (code 47JB) respectively. A PCR master mix was prepared by mixing 10X PCR buffer, dNTP mix (100mM each), $\mathrm{MgCl} 2$, Taq polymerase (3 units/ $\mu \mathrm{l})$ double distilled water and template DNA. The thermal cycling conditions were: initial denaturation at $95^{\circ} \mathrm{C}$ for 5 min followed by 40 cycles of denaturation at $95^{\circ} \mathrm{C}$ for $30 \mathrm{sec} / 1$ min, annealing at $50^{\circ} \mathrm{C}-60^{\circ} \mathrm{C}$ for $1 \mathrm{~min}$, extension at $72^{\circ} \mathrm{C}$ for $2-5 \mathrm{~min}$ and final extension at $72^{\circ} \mathrm{Cfor}$ 10 min. The PCR product and standard DNA ladder were electrophoresed in $2 \%$ agarose gel and visualized with ethidium bromide.

\subsection{DNA Sequencing}

The ITS2 regions from some of the collected specimens were amplified according to the condition described above. The PCR product of these ITS2 bands was sequenced.

\section{ObServation}

Polytene chromosome complement of ovarian nurse cells consists of five synapsed banded chromosomal arms .One of the arm is characteristically shortest and represents $\mathrm{X}$ chromosome. $\mathrm{X}$ chromosome content 1-6 zone, 2R:7-19, 2L:20-28,3R-29-37 and 3L-38-46 zones. However the marking of sub division in each zone is arbitrary (Fig: 1 A-E).

\subsection{X-Chromosome}

This chromosome is the smallest unit among the five chromosome complements and is divided into 1- 6 zones. Its centromeric end is slightly bushy and is recognized by broad and expanded area in the region $6 \mathrm{C}$ with a prominent dark band in6A\&6B. A series of faint bands are easily recognizable in the region 5 .Presence of small puff in the region $2 \mathrm{~A}$ and $3 \mathrm{C}$. Puff in the region $4 \mathrm{C} \& 4 \mathrm{D}$ followed by prominent dark band is the diagnostic feature of this chromosome complement. The free end (1A) begins with same diffuse band.

\subsubsection{R-Chromosome}

The right arm of the 2 chromosome is easily identified as the longest autosomal arm in the complement. It is divided into 7-19 regions. The free end of $2 \mathrm{R}$ is semi flared followed by a thickly stained dark band in 7A. A diffused puff with two dark bands is marked in the regions 7B and 7C. A series of dark bands are present in $8 \mathrm{~A}$ and $8 \mathrm{C}$. A small puff in $8 \mathrm{~B}$ is well marked. A series of dark bands are present in the region 9A followed by a small puff in 9C. A small puff with dark bands is well furnished in 10A. A typical puff in 11A is followed by dotted and thin dark bands in 11C. A series of thin dark bands are well marked in the region 12. Dark bands and faint bands are extended from $13 \mathrm{~A}$ to $13 \mathrm{C}$ region. A series of thickly stained dark bands are marked in the region 15 followed by a small puff in 16A. A small puff is present in 16B. A series of heavily stained dark bands are marked in the segment 17A, 17B and 17C.A series of faint bands are present in the regions 18B and 18C. The region 19 begins with a small puff followed by dark and diffused bands.

\subsubsection{Chromosome}

It is the shortest arm among the autosomal complements. It consists of 20-28 regions. The free end of this arm is recognized by two thick dark bands in the region of 28A.A Series of dark bands are present in 28B and 28C. A puff is present in 27B followed by dark bands. In A group of moderately stained dark bands are present in the region $27 \mathrm{C}$ and $27 \mathrm{~B}$. A group of moderately stained dark bands are present in the region $27 \mathrm{C}$. The region $26 \mathrm{~A}$ begins with double bands and $26 \mathrm{~B}$ contain a puff. 
Followed by faint bands. The region $25 \mathrm{C}$ begins with a series of thick dark bands and ends in $24 \mathrm{~A}$. A small puff with faint bands alternating with light bands characterizes.

The region 23C. A small puff in 21A and three dark bands are present in 22B followed by small puff in the region 21A. Two dark bands are present in 21B. The diagnostic feature in this chromosome complement is the presence of an asynapsis in 20B region.

\subsubsection{R Chromosome}

The right arm of the chromosome three i.e $3 \mathrm{R}$ and contain 29 to 37 regions. It is easily recognized by its vase shaped or funnel shaped free end in 29 A region followed by a small puff with thin bands in 29B .The diagnostic feature of this chromosome complement is the presence of a series of dark bands extends from 29C to 29D. A small puff is present in the region 30A, 30B, and 30C with dark bands. A series of dark band in 31 a region. Three dark bands extend from $32 \mathrm{C}$ to $33 \mathrm{~A}$. Thick and thin band are housed in 33B. Dark bands are overlapped in region 34. A series of thin band present in the region 35. In region 36 thin bands are present. A series of dark and faint bandsalong with a small puff is present in the region 37.

\subsubsection{Chromosome}

The left arm of the chromosome 3 i.e. 3L consist of 38-46 regions. Lightly stained free end of this arm is followed by extremely thick dark bands at $46 \mathrm{~A}$ followed by small puff in the region $46 \mathrm{~B}$. A small puff at $45 \mathrm{~A}$ and $45 \mathrm{~B}$ is followed by a constriction at $45 \mathrm{C}$ is the characteristic feature towards the free end of this chromosome complements. The region 44 as whole consist of a series of dark bands with a small puff begins at 44A. A nice puff in the region 44B and 44C contains doublets and dark bands. The region 43 begins with dark bands followed by a small puff . A large puff in the $43 \mathrm{C}$ is the land mark for this complements. Two dark bands mark in the region $42 \mathrm{~A}$ and $42 \mathrm{~B}$. The region $42 \mathrm{C}$ has small puff with dotted bands. The region 41 as whole appears as lightly stained with a single dark band. A single thick dark band presence at the constriction 41B \&41C.followed by small puff in the region 42Dwith doublets. A group of thick dark bands with a small puff is present in the region 40C and 40D and forms a significant land mark. A series of dark bands also appear in 39A followed by small puff in 39B and 39C with dark bands. The region 39D has thin bands often appears variables in their staining intensity. The bands present in region 38 as whole, usually followed by a series of thickly stained dark bands which characterize the centromeric end of this chromosome complements.

Table1. Key features of ovarian nurse cell polytene chromosome complements

\begin{tabular}{|l|l|}
\hline Chromosome & Diagnostic feature (Puff) \\
\hline $\mathrm{X}$ & $1 \mathrm{~A}, 3 \mathrm{C}$ \\
\hline $2 \mathrm{R}$ & $8 \mathrm{~B}, 11 \mathrm{~A}, 16 \mathrm{~B}$ \\
\hline 2L & $27 \mathrm{~A}, 27 \mathrm{~B}, 23 \mathrm{C}, 22 \mathrm{~A}$ \\
\hline $3 \mathrm{R}$ & $27 \mathrm{~B}, 32 \mathrm{C}$ \\
\hline $3 \mathrm{~L}$ & $39 \mathrm{~B}, 40 \mathrm{C}, 40 \mathrm{D}, 42 \mathrm{C}, 44 \mathrm{~A}, 44 \mathrm{~B}, 44 \mathrm{C}$. \\
\hline
\end{tabular}

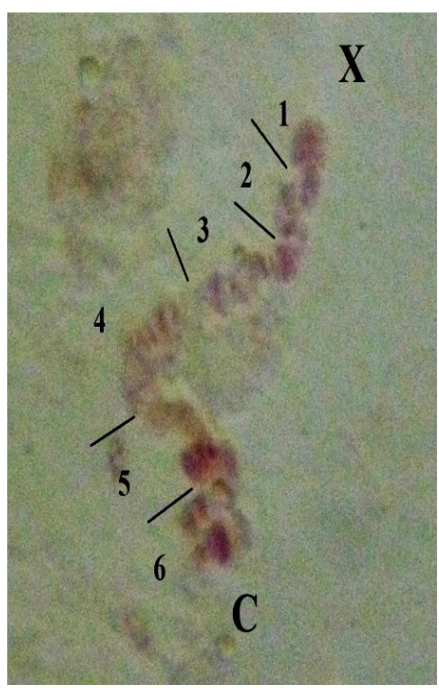

Fig1(A). X Chromosome 


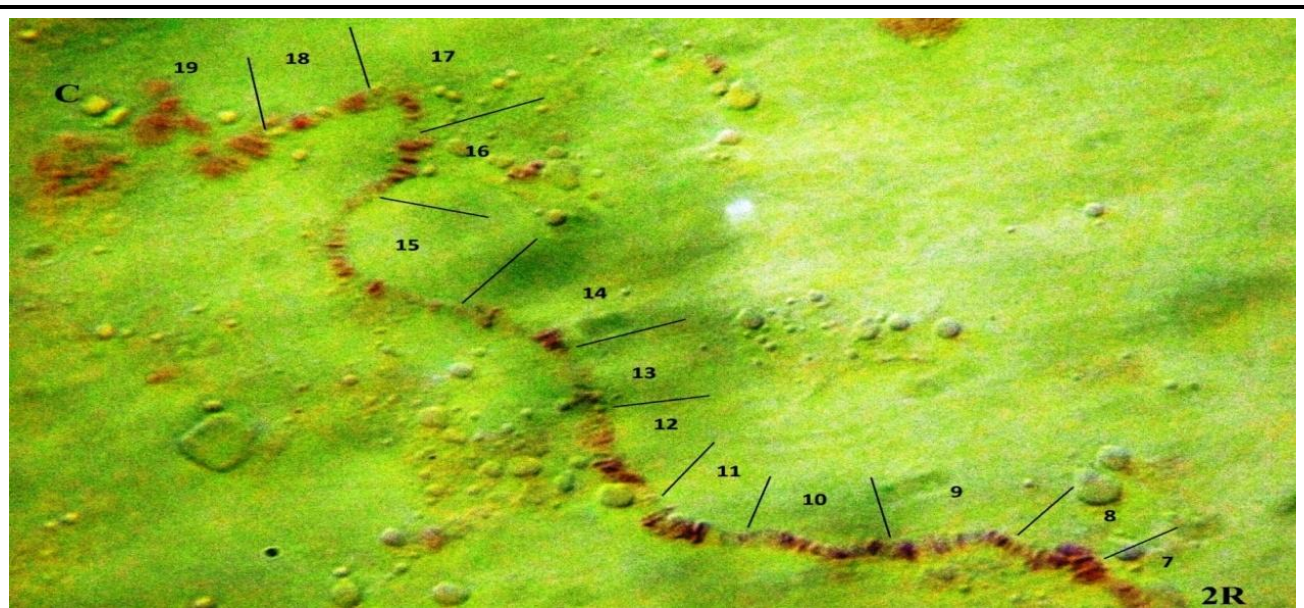

Fig1(B). 2R chromosome complement

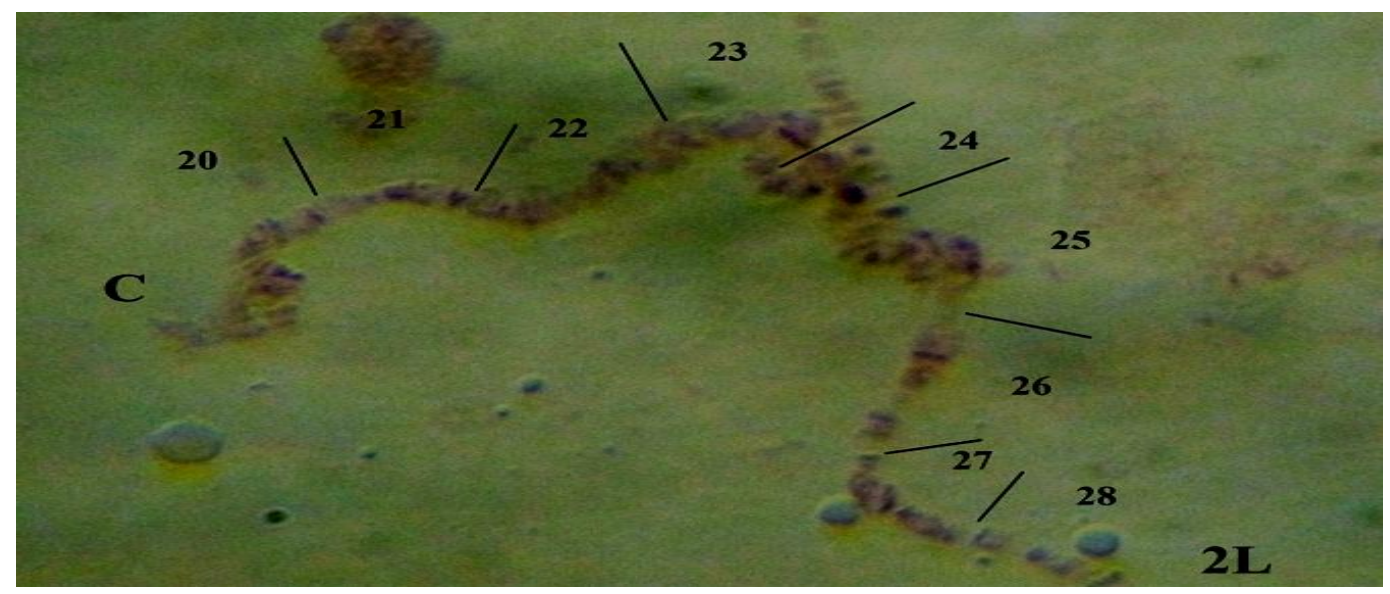

Fig1(C). 2 L Chromosome complement
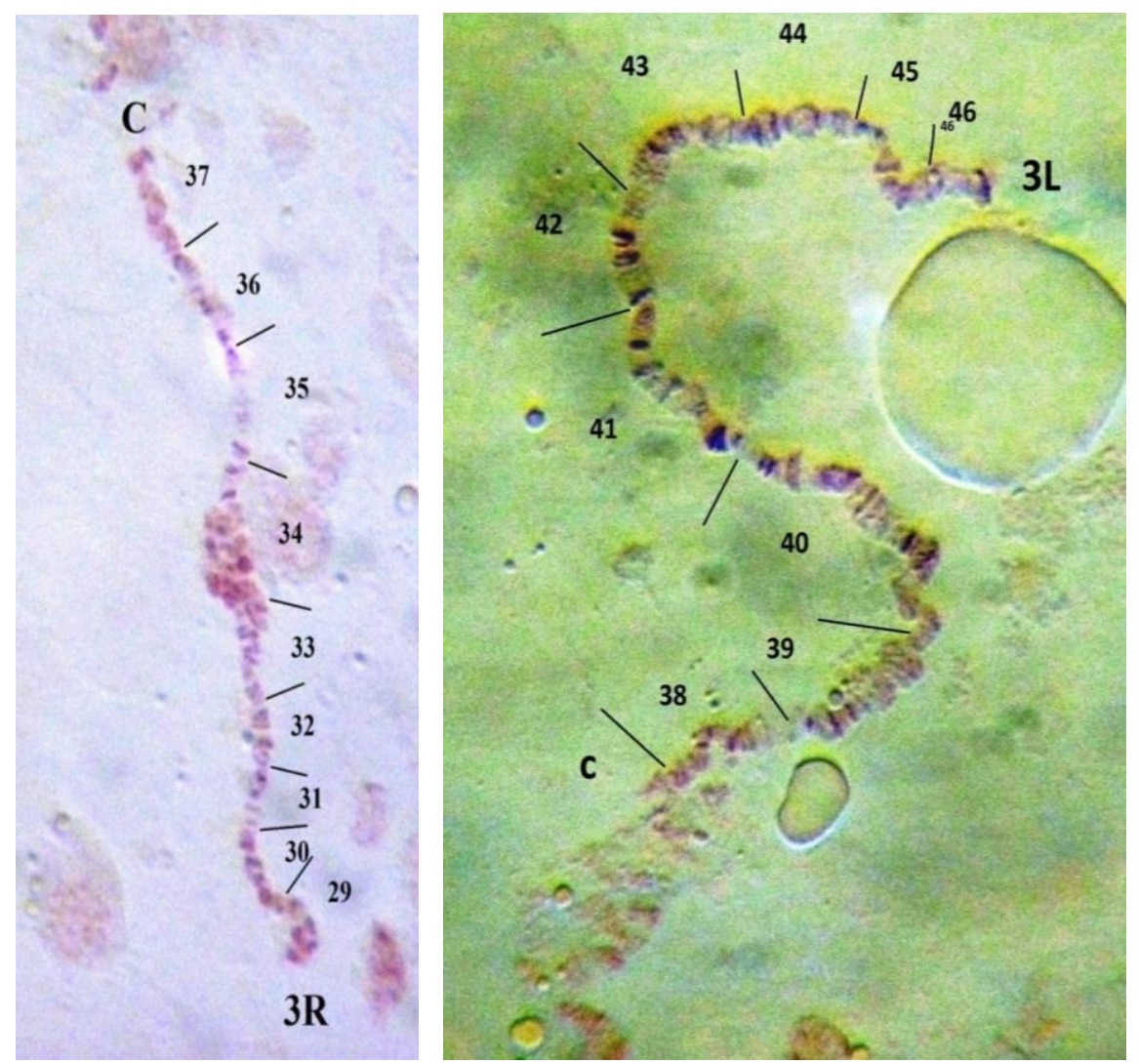

Fig1(D). 3R Chromosome complement

Fig1(E). 3 L Chromosome complement

Fig1(A-E). Ovarian nurse cell polytene chromosome of An. vagus 
Cytological and Molecular Studies Based on Ovarian Nurse Cell's Polytene Chromosome and ITS-2 Sequence of Anopheles vagus in West Bengal

3.6.ITS2 Sequence of An. vagus (KT716079)

\subsubsection{An. vagus}

TAAGGAGTGCAAACGCTGAGAGACGCATGCGCAGTGCCGCAAGACTTGTCACATTCAGG CCCCAAGTGTACGCGAGAGCACCGAGTCACGCCTGCTGCACAGTGCATCGCGGACAAAG ATGCCCGTCAGCCCCTTAGAGCGCCGTGTGCGTACAAGTCTATAGATAAATACTCAGTAC ACGTAGGCACTCACGATGTGTGCATCTGTCTGGTGAAACGTCCGTTGCCAAAGGCAATAA AAGGGAATTTTTTGAAATATTCCGCACACGAACACCGATAAGTTGAACGCATATGGCGC ATCGGACGTTTCAACCCGACCGATGCACACATCCTTGAGTGCCTACTAGGTACTGAGATT TAACTATGACTTGACTACAGACGGCGCCACTAAAGGGCTGACGGGCCATCCGTCGTCCG GCGTGCGACTGTGCAGCATGGCGTGCTCGGGTCTCGGCGTGGACCCTTGGGCGCTGAAA GTGGACACTGTTTGGCGGCACCTGCGCGTGTGCTCTCAGTGTTGACGTATGGTGAGGGTA GTGTCAAGTCGCACGGTTCGACAACAAGCGTACCGTCGAGTTTGGTGCAATCGGATGCCT ACTACCATGGGCGGTGCCGGCGTGCATTCAACACACTCGACGTCCCGTACCAACCGGAT GCCTGTGAAGGCGGTGCCGGCGCAGACGGGACACTGAATTGATCTTGGTGATATTGGGG GATGATGGATGATGTGTGTCGCGAGTGACAACCGGATGCCAGCGATGGCGGTGCCGGCG CACACGAGCGCTCACACACGCCTCTCCCCTCGGTCGCTTGTGGCGTGTAACGCGTGTGA.

Fig2. ITS2 sequence of An.vagus

Table2. Characteristic Feature of ITS2 Sequence of An. vagus:

(A): Base pair length and GC content of ITS2 region of An. vagus:

\begin{tabular}{|l|l|l|}
\hline Species & Bp & GC content \\
\hline An.vagus & 831 & $56.8 \%$ \\
\hline
\end{tabular}

(B): Repeat sequence of ITS2 region in An. vagus:

\begin{tabular}{|l|l|}
\hline Name of repeat sequence & An. vagus \\
\hline Dimers & \\
\hline AC & 130 \\
\hline TG & 138 \\
\hline CA & 138 \\
\hline Trimers & \\
\hline GTG & 48 \\
\hline Tetramers & \\
\hline CCTA & 4 \\
\hline GCAT & 13 \\
\hline CGTG & 15 \\
\hline GTGC & 23 \\
\hline TGCA & 16 \\
\hline GCGT & 16 \\
\hline Pentamers & \\
\hline GGTGC & 6 \\
\hline Polymers & \\
\hline GACGTG & 0 \\
\hline CTCGGCGTG & 1 \\
\hline
\end{tabular}

No tandem repeat found in An.vagus

\section{DISCUSSION}

Present investigation reveal the detailed structure (banding and puffing pattern) of ovarian nurse cell polytene chromosome (Fig-1A-E) of An. vagus. It should be mentioned here that the chromocenter is generally absent in Anopheles mosqitoes. X chromosome is very short among the other polytene chromosome complements. Second autosome complement $(2 \mathrm{R})$ is the longest and $2 \mathrm{~L}$ is short but the third autosomal complement $3 \mathrm{R}$ and $3 \mathrm{~L}$ are more or less in same length. The data (Table: 1 ) reveal the key features of different arms of polytene chromosome of An. vagus. The data (Table-1) reveal the puffing pattern among the different arms of polytene chromosome. Our investigation has not only confined to cytological basis but also extended at molecular level. Our molecular studies have been conducted to characterize ITS2 sequence of An. vagus (Fig-2). The data (Table: 2A ) reveal that the base pair length of ITS2 sequence of An. vagus is $831 \mathrm{bp}$ and the GC content is about $56.8 \%$. The data (Table: 2B) suggest that presence of tetramers, pentamers ,polymers and absence of tandem 
repeat in ITS2 sequence of An.vagus in natural population (some areas) of West Bengal. The data (Table: 2B) also indicate the presence of tetramer TGCA which encodes a restriction site for enzyme HpyCH4IV in An. vagus.

\section{ACKNOWLEDGEMENT}

The authors are grateful to Dr.Vansanglura, Principal, Serampore College, for providing facilities to carry out the present work. Authors are also grateful to Dr. S.KSubarao, Dr. A.P Dash, B.K. Tyagi and Dr.B.Nagpal for their constant inspiration and co-operation.

\section{REFERENCES}

[1] Alam M.S., Khan MGM, Chaudhury M, Delor S., Najib F ., Bangali M Haque R.Prevalence of Anopheline species and their Plasmodium infection status in epidemic prone border areas of Bangladesh. Malar J.9:15. .(2010)

[2] Ausubel FM., Breut R, Kingston R E., Moore DD., Sideman JG., Smith JA, and Struhl K. Short protocols in molecular biology, John- Wiley and Sons Inc U.K. 4: 15Pp.1-37. (1999).

[3] Baker R.H. \& Kitzmiller J.B.. Salivary gland chromosome of An.punctipennis.J.Hered.55:9-17. (1964).

[4] Banerjee P.K. Inversion polymorphism in natural population of Anopheles subpictus in West Bengal. Proceedings of the Second Symposium on Vector \&Vector Borne Disease. pp 118-122. (1997).

[5] Banerjee PK, and Chatterjee RN, Polytene chromosome of Anopheles subpictus I banding and puffing patterns Proceedings of the International Symposium on Vectors And Vectors borne diseases, pp 104-110(1994).

[6] Chowdaiah BN, Avirachan TT, Setharam MP. (1967), Salivary gland chromosomes in four species of tropical anophelines: A. subpictus, A. vagus, A. hyrcanus nigerrimus and $A$. barbirostris. 65, (5), pp 181-184.

[7] Christophers SR. The Fauna of British India, including Ceylon and Burma, Diptera. Vol. IV, family Culicidae, tribe Anophelini. Taylor and Francis, Red Lion Court, Fleet Street, London. (1933).

[8] French, WL, Baker R.H. and Kitzmiller J.B : Preparion of mosquito chromosome. Mosquito News 22.4:377-383.(1962)

[9] Goswami G: PCR-RFLP of mitochondrial cytochrome oxidase sub unit II and ITS 2 of riobosomal DNA markers for the identification of members of Anopheles culicifacies complex (Diptera : Culicidae) Acta Tropica 95:92-99.(2005).

[10] Kaur J Reporting on morphological variation on wings and Palpi in Anopheles (Cellia) fluviatilis james and Anopheles (Cellia) vagus Donitz journal of Entomology an Zoology studies 4(1): 402-405 (2o16) 63(2),124 (2010)

[11] Kaura, T,Sharma M, Chaudhry S and Chaudhry A. :A sequence of polymorphism in spacer ITS2 of Anopheles (Cellia) subpictus Grassi (Dipter : culicidae. Caryogia 63(2)124 (2010).

[12] Mahmood F and Sakai PK: Inversion polymorphism of Anopheles stephensi Can.J.Gen Cytol.26:538-546. (1984)

[13] Nagpal BN, Srivastava A, Saxena R, Ansari MA, Dash AP, Das SC. Pictorial identification key for Indian Anophelines. New Delhi Malaria Research Center (ICMR). (2005).

[14] Paul S, Chattopadhyay A and Banerjee PK "Anopheline Diversity: Morphological and Molecular Variation of An. subpictus in Rural and Urban Areas of West Bengal" Journal and Entomology And Zooloogy Studies Volume 1 Issuue 2:35-40(2013).

[15] Paul S, Chattopadhyay A, and Banerjee PK. "Studies on seasonal abundance \& molecular characterization of An. subpictus and An. vagus on ITS2 sequence variability". International journal of Malaria Research, 2(3):131-135. (2015).

[16] Saifuddin,U.T. Baker RH and Sakai RK, the chromosome of Anopheles culicifacies. Mosquito News.38 (2):233-239. (1978).

[17] Sakai R K, Mahmood F, Akhtar K, Dubash CJ, Baker RH . Induced chromosomal aberration and linkage group correlation in An .stephensi. J Hered. 74(4):232-8. (1983).

[18] Subbarao, SK., Vasantha K , Adak T and Sharma VP. Anopheles culicifacies complex:evidence for new sibling species, species C. Ann. Entomol. Soc. Am. 76:985-988. (1983).

[19] Walton C, Sharpe RG, Pripchard SJ. Thelwell NJ and Butlin RK. Molecular identification of mosquito species. Biol J Linn Soc.; 68:241-256. (1999). 